\title{
IgA Nephropathy Associated with Portal Hypertension in Liver Cirrhosis due to Non-Alcoholic and Non-A, Non-B, Non-C Hepatitis
}

\author{
Morio Nakamura, Akira Ohishi, Reiko Watanabe, Kohtaro Kaneko, Noboru Aosaki, Tomohiko Iigaya*, \\ Tetsuo Monma*, Hitoshi Sugiura**, Yukari Miyoshi** and Kinichi Hamaguchi***
}

\begin{abstract}
A 69-year-old female was admitted to our hospital because of leg edema, proteinuria $(2.1 \mathrm{~g} /$ day), and gross hematuria. She had non-alcoholic liver cirrhosis of unknown etiology. Esophageal varices also were found. Examination of the renal biopsy specimen revealed mesangial proliferative glomerulonephritis with IgA deposits. Propranolol was administered orally to reduce portal hypertension, resulting in a progressive decrease in urinary microalbumin excretion. This case suggests that portal hypertension is involved in the pathogenesis of IgA nephropathy in liver cirrhosis.
\end{abstract}

(Internal Medicine 33: 488-491, 1994)

Key words: mesangial proliferative glomerulonephritis, $\beta$-blocker, liver disease

\section{Introduction}

Chronic liver diseases, especially alcoholic liver cirrhosis and viral hepatitis, are known to be associated with renal glomerular changes (1-3). IgA nephropathy in liver cirrhosis was first reported in 1970 and has been one of the wellrecognized complications of liver cirrhosis (4). Although current reports have suggested that this nephropathy is mediated by immune complexes containing IgA, the pathogenesis remains uncertain (5-10). Recently, it was reported that splenectomy and a portocaval shunt led to the remission of proteinuria and hematuria in patients with $\operatorname{IgA}$ nephropathy and portal hypertension $(11,12)$.

In this report, we describe a case of liver cirrhosis due to nonalcoholic and non-A, non-B, non-C hepatitis that developed IgA nephropathy. Propranolol, which is known to reduce portal hypertension $(13,14)$, caused a progressive decrease in urinary microalbumin excretion. The possibility that portal hypertension plays a crucial role in the pathogenesis of IgA nephropathy in liver cirrhosis is also discussed.

\section{Case Report}

A 69-year-old female was admitted to our hospital suffering from leg edema and reduced urine volume. She had been followed at a local clinic for 3 years because of slight liver dysfunction, with no abnormal findings on urinalysis. Four months prior to the present admission, she was admitted to our hospital with acute pancreatitis probably caused by a gallstone, and treated conservatively. At that admission, she had presented with minimal proteinuria and microscopic hematuria. She had no history of a blood transfusion or alcohol consumption.

On physical examination, her body weight was $58 \mathrm{~kg}$ and height $133 \mathrm{~cm}$. Blood pressure was $136 / 74 \mathrm{mmHg}$, and pulse rate $100 / \mathrm{min}$. The abdomen was distended; ascites and moderate pitting edema in both legs were present. Heart sounds were normal. No crackles were heard over the lungs.

Laboratory data at the second admission were: leukocyte count $7,700 / \mathrm{mm}^{3}$, hemoglobin $11.8 \mathrm{~g} / \mathrm{dl}$, platelet count 147,000 / $\mathrm{mm}^{3}$ and prothrombin time $12.2 \mathrm{sec}(67 \%)$. Serum total protein was $6.6 \mathrm{~g} / \mathrm{dl}$ (including 36\% $\gamma$-globulin), albumin $2.0 \mathrm{~g} / \mathrm{dl}$, glutamic oxalacetic transaminase $46 \mathrm{IU} / \mathrm{l}$, glutamic pyruvic transaminase $25 \mathrm{IU} / \mathrm{l}, \gamma$-glutamyl transpeptidase $61 \mathrm{IU} / \mathrm{l}$, cholinesterase $97 \mathrm{IU} / \mathrm{l}$, total bilirubin $0.7 \mathrm{mg} / \mathrm{dl}$, tymol turbidity test $10.0 \mathrm{~K} / \mathrm{U}$, zinc turbidity test $28.6 \mathrm{~K} / \mathrm{U}$, creatinine $1.1 \mathrm{mg} / \mathrm{dl}$, and blood urea nitrogen $22 \mathrm{mg} / \mathrm{dl}$. The 15 -min retention of indocyanine green was $43.0 \%$. Serum IgG was $2,318 \mathrm{mg} / \mathrm{dl}$,

\footnotetext{
From the Department of Internal Medicine and *Urology, Kasumigaura National Hospital, Tsuchiura, **the Department of Pathology, School of Medicine, Keio University, Tokyo and ***the Department of Pathology, Sakura National Hospital, Sakura

Received for publication November 8, 1993; Accepted for publication May 26, 1994

Reprint requests should be addressed to Dr. Akira Ohishi, the Department of Internal Medicine, Kasumigaura National Hospital, 2-7-14 Shimotakatsu, Tsuchiura, Ibaraki 300
} 
IgA $741 \mathrm{mg} / \mathrm{dl}$, IgM $159 \mathrm{mg} / \mathrm{dl}$. Serum complements were normal. Tests for surface antigen and e antigen of hepatitis virus $\mathrm{B}$ and serum antibody of hepatitis virus $\mathrm{C}$ were negative. The serum rheumatoid factor, antinuclear antibody, anti-DNA antibody, anti-neutrophil cytoplasmic antibody, anti-smooth muscle antibody and anti-mitochondria antibody were all negative. The serum cryoglobulins and circulating immune complexes were not detected. The 24-hour urinary excretion of total protein and microalbumin were $2,100 \mathrm{mg}$ and $1,030 \mathrm{mg}$, respectively. The urine sediment showed many red blood cell casts per high power field. The creatinine clearance was $42 \mathrm{ml} / \mathrm{min} / 1.73$ $\mathrm{m}^{2}$. The findings of X-ray, ultrasonic cardiography, cystoscopy and intravenous pyelography were normal. Abdominal computed tomographic scanning revealed an atrophic right hepatic lobe and ascites. Upper gastrointestinal endoscopy showed white varices.

Needle renal biopsy was performed 15 days after admission. Light microscopic examination demonstrated mesangial proliferation in almost all glomeruli with cellular crescents in a few of them (Fig. 1). Immunofluorescence studies revealed 2+ staining for $\operatorname{IgA}$ and $\mathrm{C} 3$ in the mesangial area (Fig. 2). Electron microscopic examination showed increased mesangial matrix and paramesangial and mesangial electron dense deposits (Fig. 3). Needle liver biopsy performed to disclose the etiology of the liver disease showed fibrosis with the formation of regenerative nodules and inflammatory cellular infiltration. There was no evidence of autoimmune hepatitis, alcoholic liver cirrhosis, or biliary cirrhosis. Based on these findings, this patient was

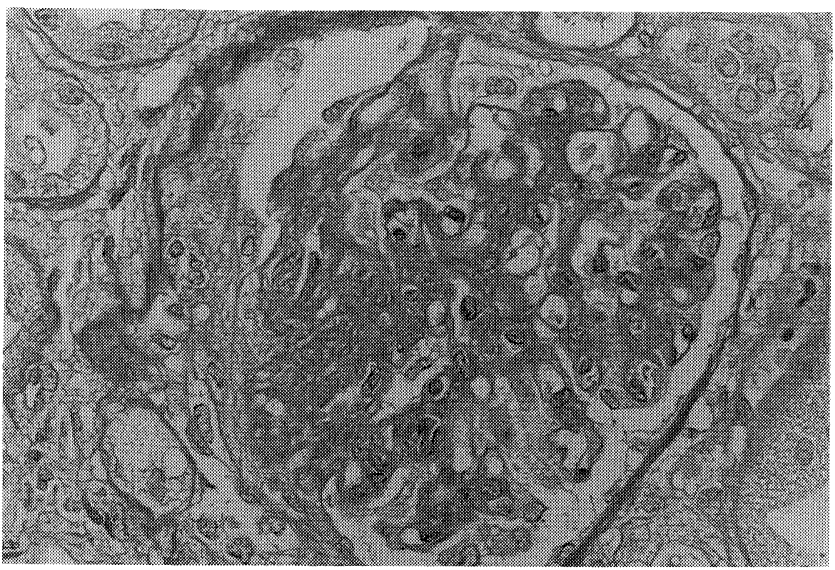

Fig. 1. Light micrograph of the glomerulus, showing mesangial proliferation and cellular crescents (PAS stain, $\times 132$ ).

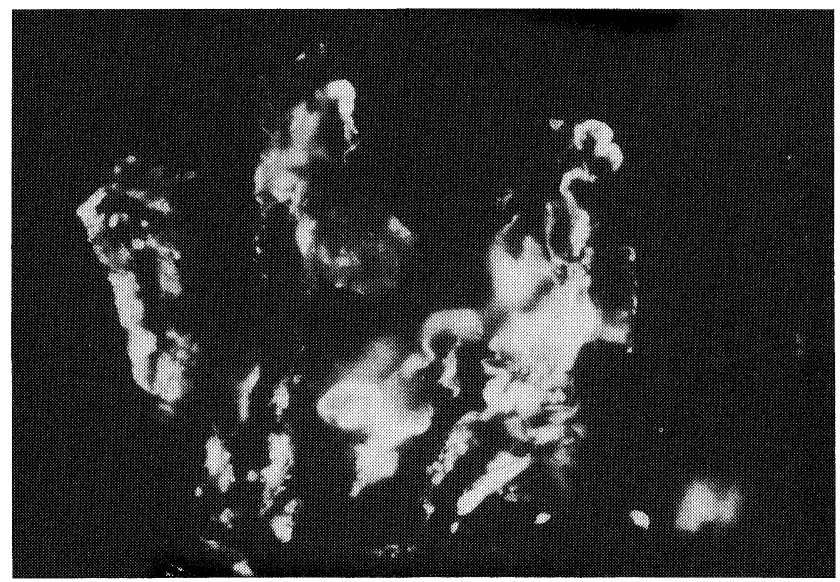

Fig. 2. Immunofluorescence micrograph of the glomerulus, showing mesangial staining for IgA $(\times 200)$.

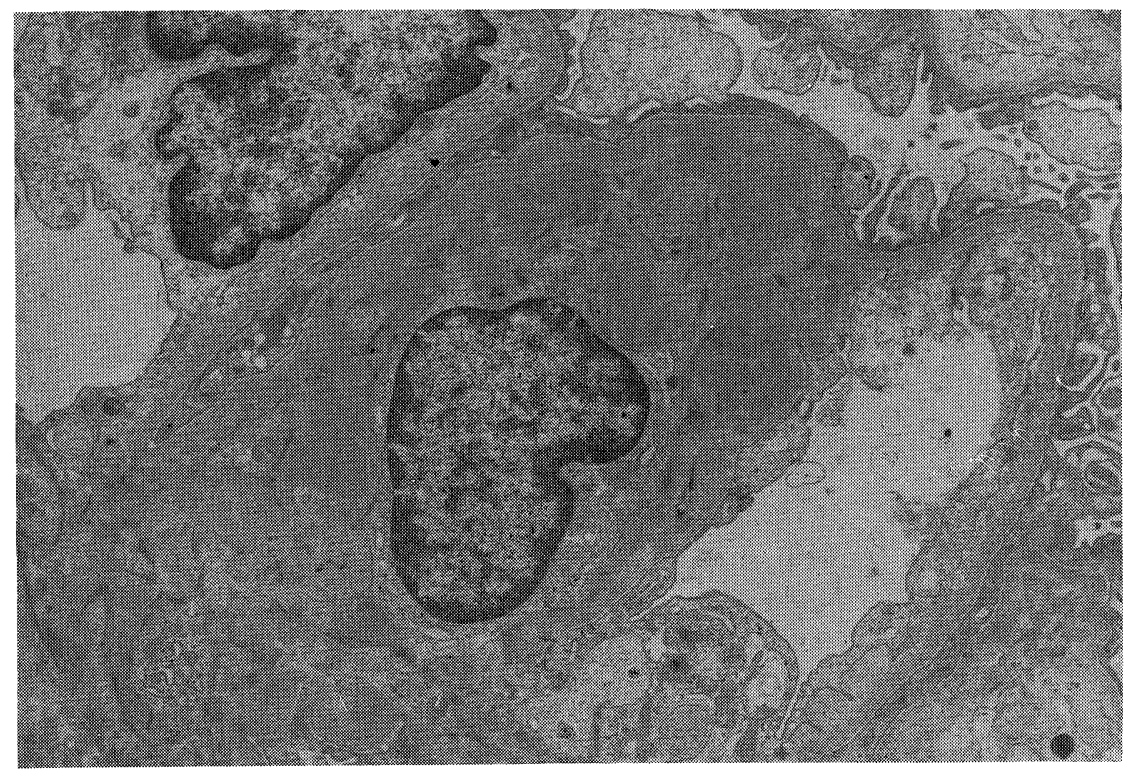

Fig. 3. Electron micrograph of the glomerulus, showing paramesangial and mesangial electron dense deposits $(\times 5,300)$ 


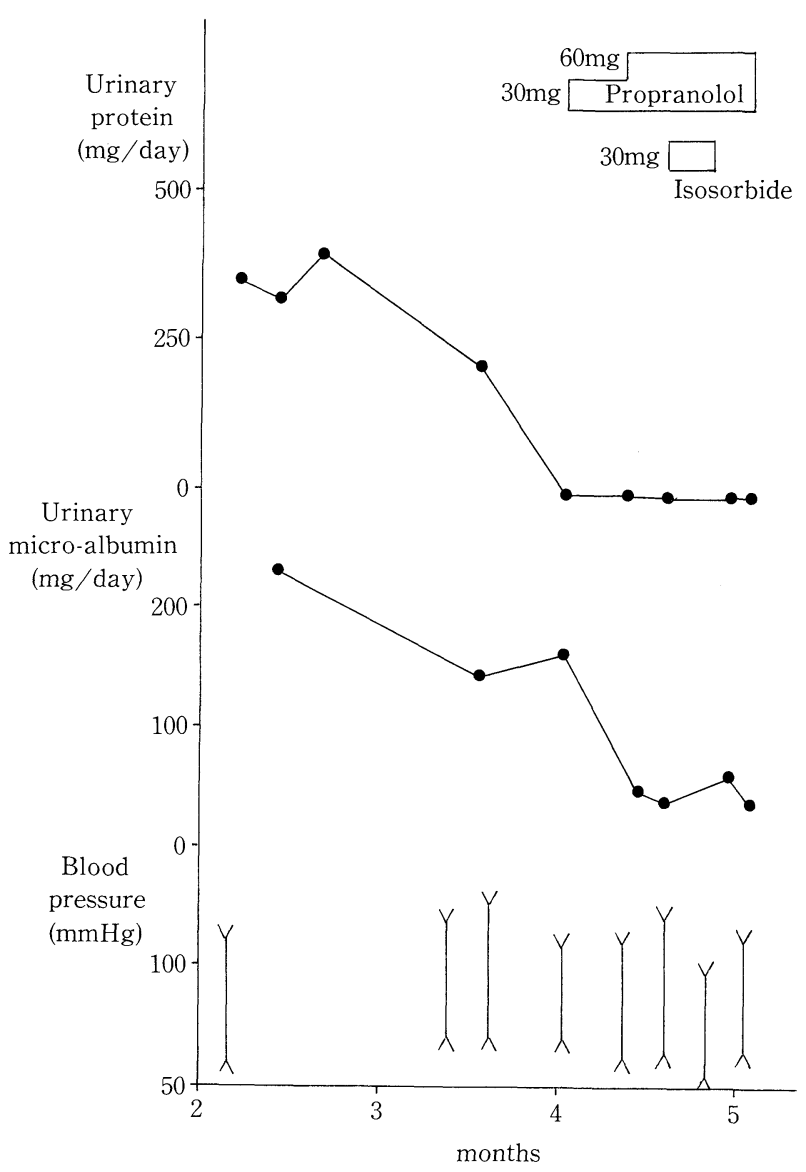

Fig. 4. Clinical course, presenting relation between urinary protein, microalbumin excretion and administration of propranolol.

diagnosed with IgA nephropathy and liver cirrhosis due to nonalcoholic and non-A, non-B, non-Chepatitis. Four months after the first admission, 24-hour urinary protein excretion had increased from $450 \mathrm{mg}$ to $2,100 \mathrm{mg}$. As a result of dietary protein restriction $(45 \mathrm{~g} / \mathrm{day})$ and oral administration of dipyridamole $300 \mathrm{mg} /$ day and dilazep $300 \mathrm{mg} /$ day, in addition to diuretics (furosemide, spironolactone), urinary protein excretion decreased to $500 \mathrm{mg} /$ day. Captopril had no obvious effects on urinary protein excretion.

Three months after her admission, oral propranolol (30 mg/ day for one week, then increased to $60 \mathrm{mg} /$ day) was added. Blood pressure showed no marked changes. Moreover, after two weeks, isosorbide ( $30 \mathrm{mg} /$ day), which enhances the effect of propranolol probably by a vasodilatory effect on the portal venous system, was added $(15,16)$. Because of dizziness and a fall in blood pressure, however, isosorbide was discontinued. Initiation of propranolol led to the disappearance of urinary protein excretion and a progressive decrease in urinary microalbumin excretion (from $165 \mathrm{mg} /$ day to $43 \mathrm{mg}$ /day in one month) (Fig. 4). There were no changes in hematuria.

\section{Discussion}

Renal glomerular changes in patients with liver cirrhosis were first noted in 1942 by Horn and Smetana (17). These lesions have been reported to be mainly mesangial proliferative changes with predominant $\operatorname{IgA}$ and $\mathrm{C} 3$ deposition in immunofluorescence studies, and it has also been mentioned that these lesions are similar to primary IgA nephropathy $(1,4$ 9, 18-21). These glomerular changes have been reported in patients with advanced liver disease due to various etiological factors such as alcohol abuse, viral hepatitis, cystic fibrosis and experimental cirrhosis $(5,6,16,21-23)$. Although IgA nephropathy in liver cirrhosis is usually a clinically silent disease, it may present proteinuria, slight hematuria and granular casts in severe cases $(6,19)$.

Current studies suggest that in $\operatorname{Ig}$ A nephropathy in liver cirrhosis, the glomerular deposits may be derived from circulating immune complexes containing IgA from the gastrointestinal tract and intestinal antigens (5-10, 24-27). In liver cirrhosis it is suggested that the phagocytic activity of the liver and spleen is markedly reduced, so that impaired clearance of circulating gastrointestinal immune complexes allows them to enter the systemic circulation via portacaval shunts, leading to glomerular mesangial deposition $(9,16-18,20,24-29)$. However, the complete pathogenesis of IgA nephropathy associated with liver disease remains uncertain. The present patient showed IgA nephropathy with liver cirrhosis due to non-alcoholic and non-A, non-B, non-C hepatitis, in which oral propranolol, but not captopril, resulted in a progressive decrease in urinary microalbumin excretion. It is known that the angiotensin converting enzyme inhibitors reduce intraglomerular pressure by decreasing efferent resistance, leading to a remission of proteinuria (30). However, in the present case, captopril had no effect on urinary protein excretion. Moreover, propranolol has no ability to reduce intraglomerular pressure. Also in the present case, propranolol hardly reduced blood pressure. On the other hand, it has been reported that oral propranolol reduces portal hypertension in patients with liver cirrhosis by reducing portal tributary blood flow that may result from decreased cardiac output and direct or reflex-mediated splanchnic vasoconstriction $(11,12)$. Thus, it is suggested that oral propranolol led to a decrease in urinary microalbumin excretion by reducing portal hypertension.

There have been two case reports indicating that portal hypertension is involved in the pathogenesis of IgA nephropathy in liver cirrhosis. Laurent and colleagues reported a case of IgA glomerulonephritis with alcoholic liver steatosis, in which the portal pressure decreased from 30 to $18 \mathrm{~cm} \mathrm{H}_{2} \mathrm{O}$ after a portocaval anastomosis, and proteinuria and hematuria disappeared (11). Babbs and colleagues reported a case of IgA nephropathy with non-cirrhotic portal hypertension (12). In that case, splenectomy and resection of the splenic artery aneurysm induced the remission of nephrotic syndrome and hematuria.

Based on the above findings, the significance of portal hypertension and portosystemic shunting in the pathogenesis of 


\section{IgA Nephropathy and Portal Hypertension}

IgA nephropathy in liver cirrhosis is suggested. The present case was one of IgA nephropathy in liver cirrhosis, in which propranolol, for the first time to our knowledge, was considered to have reduced urinary microalbumin excretion by lowering portal hypertension. The severity of proteinuria is a marker of the prognosis of IgA nephropathy $(31,32)$. Furthermore, there are findings indicating that microalbuminuria may be a predictor of more severe renal damage in IgA nephropathy, as well as in diabetic nephropathy (33). This corresponds with the hypothesis that this nephropathy is closely related to portal hypertension and portosystemic shunting, which play a crucial role in the pathogenesis of IgA nephropathy in liver disease. We think that further case reports will be required to establish this hypothesis more firmly.

\section{References}

1) Bloodworth JMB Jr, Sommers SC. Cirrhotic glomerulosclerosis: a renal lesion associated with hepatic cirrhosis. Lab Invest 8: 962, 1959.

2) Fisher ER, Hellstrom HR. The membranous and proliferative glomerulonephritis of hepatic cirrhosis. Am J Clin Pathol 32: 48, 1959.

3) Jones WT, Rao DRG, Braunstein $\mathrm{H}$. The renal glomerulus in cirrhosis of the liver. Am J Pathol 39: 393, 1961.

4) Manigand G, Morel-Maroger L, Simon J, et al. Lesions renales glomerulaires et cirrhose du foie. Note preliminaire sur les lesions histologiques du rein au cours des cirrhoses hepatiques, d'apres 20 prelevements biopsiques. Rev Eur Etud Clin Biol 15: 989, 1970.

5) Callard P, Feldmann G, Prandi $P$, et al. Immune complex type glomerulonephritis in cirrhosis of the liver. Am J Pathol 80: 329, 1975.

6) Nochy D, Callard P, Bellon B, Bariety J, Druet P. Association of overt glomerulonephritis and liver disease: a study of 34 patients. Clin Nephrol 6: 422,1976 .

7) Berger J, Yaneva H, Nabarra B. Glomerular changes in patients with cirrhosis of the liver. Adv Nephrol 7: 3, 1977.

8) Sancho J,Egido J, Sanchez-Crespo M, Balasco R. Detection of monomeric and polymeric IgA containing immune complexes in serum and kidney from patients with alcoholic liver disease. Clin Exp Immunol 47: 327 , 1982.

9) Sinniah R. Heterogeneous IgA glomerulonephropathy in liver cirrhosis. Histopathology 8: 947, 1984.

10) Nochy $D$, Druet $P$, Bariety J. IgA nephropathy in chronic liver disease. Contr Nephrol 40: 268, 1984.

11) Laurent J, Lagrue G, Bruneau C, Kazandjian M. Does portal hypertension play a role in IgA mesangial glomerulonephritis ( $\mathrm{IgG} \mathrm{GN})$ ? Kidney Int 30: 640, 1986 (Abstract).

12) Babbs C, Warnes TW, Torrance HB, Ballardie FW. IgA nephropathy in non-cirrhotic portal hypertension. Gut 32: 225, 1991.

13) Lebrec D, Hillon P, Munoz C, Goldfarb G, Nouel O, Benhamou JP. The effect of propranolol on portal hypertension in patients with cirrhosis: a hemodynamic study. Hepatology 2: 523, 1982.

14) Lebrec D. Current status and future goals of the pharmacologic reduction of portal hypertension. Am J Surg 160: 19, 1990.

15) Garcia-Pagan JC, Navasa M, Bosch J, Bru C, Pizcueta P, Rodes J. Enhancement of portal pressure reduction by the association of isosorbide5 -mononitrate to propranolol administration in patients with cirrhosis. Hepatology 11: 230, 1990.

16) Garcia-Pagan JC, Feu F, Bosch J, Rodes J. Propranolol compared with propranolol plus isosorbide-5-mononitrate for portal hypertension in cirrhosis. A randomized controlled study. Ann Intern Med 114: 869, 1991.

17) Horn RC Jr, Smetana H. Intercapillary glomerulosclerosis. Am J Pathol 18: $93,1942$.

18) Nakamoto $Y$, Iida $H$, Kobayashi $K$, et al. Hepatic glomerulonephritis. Characteristic of hepatic IgA glomerulonephritis as the major part. Virchows Arch. (Pathol Anat) 392: 45, 1981.

19) Newell GC. Cirrhotic glomerulonephritis: incidence, morphology, clinical features, and pathogenesis. Am J Kid Dis 9: 183, 1987.

20) Eknoyan G. Glomerular abnormalities in liver disease. in: The Kidney in Liver Disease, Epstein M, Ed. Elsevier, New York, 1983, p. 119.

21) Endo $Y$, Matsushita $H$, Nozawa $Y$, et al. Glomerulonephritis associated with liver cirrhosis. Acta Pathol Jpn 33: 333, 1983.

22) Gormly AA, Smith PS, Seymour AE, Clarkson AR, Woodroffe AJ. IgA glomerular deposits in experimental cirrhosis. Am J Pathol 104: 50, 1981.

23) Abramowsky CR, Swinehart GL, Dahms BB. IgA associated glomerular deposits in liver disease: studies in cystic fibrosis as a human model. Lab Invest 48: 1A, 1983.

24) Triger DR, Alp MH, Wright R. Bacterial and dietary antibodies in liver disease. Lancet 1: 60, 1972.

25) Triger DR, Alp MH, Wright R. Hyperglobulinemia in liver diseases. Lancet 1: 1494, 1973.

26) Andre F, Andre C. Cirrhotic glomerulonephritis and secretory immunoglobulin A. Lancet 1: 197, 1976.

27) Woodroffe AJ, Gormly AA, McKenzie PE, et al. Immunologic studies in IgA nephropathy. Kidney Int 18: 366, 1980.

28) Nishi T, Bahn AK, Collins AB, McClusky R. Effect of circulating immune complexes of $\mathrm{Fc}$ and $\mathrm{C} 3$ receptors of Kupffer cells in vivo. Lab Invest 44: 442, 1981.

29) Iida $H$, Izumino $K$, Matsumoto $M$, Takata M, Mizumura $Y$, Sugimoto T. Glomerular deposition of IgA in experimental hepatic cirrhosis. Acta Pathol Jpn 35: 561, 1985.

30) Tolins JP, Raij L. Antihypertensive therapy and the progression of chronic renal disease. Are there renoprotective drugs? Semin Nephrol 11: $538,1991$.

31) Neelakantappa K, Gallo GR, Baldwin DS. Proteinuria in IgAnephropathy. Kidney Int 33: 716, 1988.

32) Okada K, Funai M, Kawakami K, Kagami S, Yano I, Kuroda Y. IgA nephropathy in Japanese children and adults: a comparative study of clinicopathological features. Am J Nephrol 10: 191, 1990.

33) Widstam-Attorps UC, Berg UB. Urinary protein excretion and renal function in children with IgA nephropathy. Pediatr Nephrol 5: 279, 1991. 